\title{
WHO warns over complacency as targets on Ebola are met
}

\author{
Anne Gulland \\ London
}

An official leading the World Health Organization's response to the outbreak of Ebola virus disease in west Africa has warned against complacency as the targets set by the United Nations for safe burial and isolation are met.

At the end of October the UN's Mission for Ebola Emergency Response set two targets to be met by 1 December-that $70 \%$ of burials took place in a safe and dignified manner and that $70 \%$ of patients with Ebola were isolated.

At a press conference on 1 December Bruce Aylward, WHO's assistant director general in charge of the organisation's response to the outbreak, said that in the three worst affected countries of Sierra Leone, Liberia, and Guinea the target on safe burial had been met. The target on isolation had been met in Liberia and Guinea but not in Sierra Leone, where the epidemic is gathering pace in the west of the country, which Aylward described as a "hot spot" for the disease. But he said that the target should soon be met as more beds were made available.

"We're in a very different place than we were 60 days ago when the disease was escalating and there was a yawning gap between the response capacity and the disease. The response has been impressive and we have seen many people, organisations, and others step up," he said.

In Liberia there are now nearly 1000 beds for patients with Ebola, compared with 480 two months ago. In Sierra Leone the number of beds has increased from 267 to more than 650 over the same period. The number of burial teams has more than doubled over the past two months, from 100 to more than 200 in the three affected countries.

Aylward said that the three most affected countries were beginning to catch up with the disease, but he warned that "it doesn't mean we are automatically going to get to zero. That requires additional measures."

He said that one of the biggest dangers now was that Ebola drops off the front pages. He added that in the affected countries he had seen people taking a more lax attitude to infection control, such as cramming into taxis or forgetting to wash their hands.

As at 1 December there had been 7109 cases of Ebola in Sierra Leone, 7635 cases in Liberia, and 2155 in Guinea, bringing the total since the outbreak began in March to 16899 . This number includes 5987 deaths in the three worst affected countries. There have also been eight cases of the disease in Mali, including six deaths.

The outbreak is gathering pace in Sierra Leone, where in the last three weeks there have been 1339 cases. But it is stable in Guinea, which has seen 374 cases over the same period, and stable or declining in Liberia, where there have been 319 cases. The UN's focus is now on ensuring 100\% safe burials and $100 \%$ of patients isolated by the end of this year. Aylward said that as these targets were met the emphasis had to move to case finding and contact tracing, as is happening now in Mali. There are currently around 250 people working on surveillance, but this number needs to rise to around 400, he said.

Kevin Rudd, the former prime minister of Australia, has been appointed to lead a two year review of the UN and its institutions, such as WHO, and has called for a "substantive reform" of the global health body.

He said that WHO had a "systemic problem" in the way power was shared between the centre and its regional branches and that WHO needed the power to act globally on threats to global public health.

Meanwhile there have been promising preliminary results from a trial of an Ebola vaccine developed by the US National Institute of Allergy and Infectious Diseases and GlaxoSmithKline. A report of a phase I clinical trial showed that the chimpanzee adenovirus vector vaccine against Ebola was well tolerated and produced immune responses in all 20 healthy adult volunteers who received it. ${ }^{1}$

Access all of The BMJs content on the ongoing Ebola outbreak at thebmj.com/ebola.

1 Ledgerwood JE, DeZure AD, Stanley DA, Novik L, Enama ME, Berkowitz NM, et al. Chimpanzee adenovirus vector Ebola vaccine-preliminary report. N Engl J Med 26 Nov 2014, doi:10.1056/NEJMoa1410863. 